\title{
Fatores que Atraem e Afastam as Meninas de cursos da Área de TI
}

\author{
Amanda Martins' ${ }^{1}$, Joana Darck da Silva' ${ }^{1}$,oyce Santos ${ }^{1}$ e Ayla Dantas ${ }^{1}$ \\ Departamento de Ciências Exatas \\ Universidade Federal da Paraíba (UFPB) - Rio Tinto, PB - Brazil \\ \{amanda.azevedo, joana.darck,joyce.sousa, ayla\}@dcx.ufpb.br
}

\begin{abstract}
This paper presents the results of a survey with girls who are attending or have completed IT courses on the factors that may attract or make women less motivated to conclude courses in the area. The survey was conducted using an online form and the results show some factors that may attract girls to the area and that may be more exploited in actions with this purpose. We also obtained some factors that negatively impact the motivation of the girls to complete their courses and that should lead to more reflections in undergraduate programs and mitigated.
\end{abstract}

Resumo. Este trabalho tem o objetivo de apresentar os resultados de um levantamento junto a meninas que estão cursando ou já concluíram cursos na área de TI sobre os fatores que atraem ou dificultam a permanência de mulheres em cursos da área. O levantamento foi realizado por meio de questionário online e os resultados mostram alguns fatores que podem atrair meninas para a área e que podem ser mais explorados em ações com este fim. Foram também obtidos alguns fatores que impactam negativamente na motivação das meninas para concluírem seus cursos e que podem ser mais refletidos nos cursos de graduação e mitigados.

\section{Introdução}

A pequena representatividade de mulheres na área de tecnologia é um fato bem conhecido e se reflete nos cursos da área de Tecnologia da Informação (TI). Conforme destacado pelo Jornal do Comércio', "embora sejam 51,4\% da população brasileira, na área de TI dos cursos universitários, as mulheres ainda são minoria". Em uma consulta feita à Universidade Federal da Paraíba (UFPB) no mês de fevereiro de 2019, constatou-se que nos cursos da área de TI as mulheres correspondem a aproximadamente $14,31 \%$ dos discentes ativos e devidamente matriculados.

Existem várias pesquisas que analisam a questão de gênero na área de TI e que apontam os motivos da resistência das mulheres para entrarem na área, como é o caso do trabalho de Aires et al. (2018), e que aponta algumas barreiras que impedem a opção das meninas pelas Ciências Exatas e Computação segundo a percepção de alunas do ensino médio. Os autores levantaram como principais "empecilhos": o machismo; a ideia de que "as mulheres não são tão capazes quantos os homens" para desempenhar algum papel na área de tecnologia, o fato dos homens serem maioria nesta área; e o estereótipo atribuído pela sociedade aos profissionais que trabalham na área.

Existem diversas iniciativas cujo objetivo é "desmistificar" essas barreiras, atrair meninas para a área e apoiar as que já estão na área a concluírem seus cursos como o Meninas Digitais's, o ITGirls ${ }^{3}$ [Dantas e Figueiredo 2018], o Include Meninas ${ }^{4}$, o

\footnotetext{
https://www.jornaldocomercio.com/_conteudo/2018/02/colunas/observador/613058-faltam-mulheresna-ti.html

${ }^{2}$ http://meninas.sbc.org.br
} 
ambientAda ${ }^{s}$, cunhatã digital ${ }^{\varsigma}$, Gurias Digitais ${ }^{\gamma}$, entre outras. Visando auxiliar iniciativas como estas em suas ações, este trabalho apresenta um levantamento de dados por meio de formulários online aplicados a alunas e egressas de cursos da área e que visou estruturar fatores que levam meninas a persistir nesses cursos, dos fatores que elas consideram que podem atrair meninas para a área ou que as atraíram e dos fatores que podem diminuir a motivação das meninas durante seus cursos. $\mathrm{O}$ objetivo principal deste trabalho é conhecer melhor as opiniões de mulheres que decidem fazer cursos de TI como forma de atrair mais meninas para a área e também de buscar minimizar aspectos que impactem negativamente na motivação das alunas durante seus cursos explicitando alguns destes aspectos para que sejam tomadas ações nesse sentido.

As demais seções deste artigo estão organizadas conforme descrito a seguir. A Seção 2 discute alguns trabalhos relacionados. Na Seção 3 é detalhada a metodologia utilizada neste trabalho. A Seção 4 apresenta os resultados da análise qualitativa dos dados. Por fim, a Seção 5 apresenta as conclusões e propostas de trabalhos futuros.

\section{Trabalhos Relacionados}

Um dos trabalhos mais relacionados a este é o de Frieze e Quesenberry (2019), que destaca ações que a Universidade de Carnegie Mellon, nos Estados Unidos, tem conduzido e que têm se mostrado eficientes para aumentar a participação feminina dos cursos de computação desta instituição. $\mathrm{O}$ presente artigo se diferencia deste trabalho por focar nas opiniões de mulheres brasileiras e não nas realizações de ações em si.

Um outro trabalho relacionado é o de Almstrum e Last (2005) que fez na época um levantamento com 500 profissionais dos Estados Unidos e outros países sobre as razões para mulheres escolherem a área de computação. Esse trabalho agrupou os fatores de atração em quatro categorias: i) teoria (interesse nos conceitos da ciência da computação); ii) aplicação (interesse no uso da computação para resolver problemas e beneficiar os outros); iii) social (influência de fatores sociais e econômicos); e iv) culturais/pessoais (necessidade de desafiar os estereótipos aplicados a mulheres e à ciência da computação). O presente trabalho diferencia-se deste artigo resumido por detalhar os fatores, embora muitas vezes relacionados a estas categorias, e por apresentar os resultados com base na opinião também das atuais estudantes da área.

\section{Metodologia}

Este trabalho consiste em um estudo exploratório de caráter qualitativo. Conforme destacado por Creswell (2018, p. 8), em pesquisas qualitativas se aborda o significado que indivíduos e grupos atribuem a um problema social ou humano, estabelecendo padrões ou temas durante a análise de dados e incluindo na apresentação dos resultados as "vozes dos participantes". Este estudo exploratório visou responder às seguintes questões de pesquisa: i) Quais fatores podem atrair meninas para os cursos da área de TI? ii) Quais fatores motivam as meninas a concluírem seus cursos? iii) Que fatores diminuem a motivação das meninas durante cursos de TI?

A metodologia utilizada neste trabalho consistiu nas seguintes etapas: i) Levantamento bibliográfico de trabalhos na literatura relacionados a este trabalho; ii) Criação de dois questionários online, sendo um deles ${ }^{8}$ destinado às meninas que são

\footnotetext{
${ }^{3}$ https://itgirls.dcx.ufpb.br

${ }^{4}$ http://www2.ic.uff.br/ includemeninas/

${ }^{5}$ http://meninas.sbc.org.br/index.php/portfolio/ambientada/

${ }^{6}$ www.facebook.com/cunhantadigital

https://guriasdigitais.wordpress.com

${ }^{8} \mathrm{https} / / /$ goo.gl/KxcA8K
} 
atualmente discentes da área e outro ${ }^{9}$ às egressas de cursos de tecnologia (e.g. Ciência da Computação, Sistemas de Informação, Engenharia da Computação, Matemática Computacional, Análise e Desenvolvimento de Sistemas; e outros); iii) Divulgação do questionário em grupos de e-mails de cursos de TI da graduação da UFPB e nas redes sociais das autoras deste trabalho ou por mensagens de e-mail direcionadas a alunas da área; iv) Análise dos dados obtidos.

\section{Resultado da Análise dos Dados}

Foram obtidas 45 respostas de discentes e 12 respostas de egressas dos estados da Paraíba, Pernambuco, São Paulo, Rondônia, Ceará e Santa Catarina. A maioria $(36,8 \%)$ das respostas foi de alunas ou egressas de Sistemas de Informação (SI). Houve também uma grande parcela de mulheres que estão cursando ou já cursaram Bacharelado em Ciência da Computação (BCC), correspondente a 24,6\%, ou Licenciatura em Ciência da Computação (LCC), que foi de 17,5\%.

Percebeu-se também que entre as participantes existiram mulheres que fizeram ou estão fazendo cursos à distância na área $(10,5 \%)$, mas a grande maioria vem de cursos presenciais $(89,5 \%)$. A maioria das participantes discentes $(63,2 \%)$ é de alunas da UFPB, mas foram obtidas respostas de discentes de outras 11 instituições. Considerando as discentes, percebeu-se que elas eram de diferentes períodos de seus cursos: $13 \%$ do primeiro período; $17,8 \%$ do segundo; $4,4 \%$ do terceiro; $17,8 \%$ do quarto; $8,9 \%$ do quinto; $8,9 \%$ do sexto; $13,3 \%$ do sétimo; $2,2 \%$ do oitavo; $2,2 \%$ do nono; e $11,1 \%$ do décimo período ou de algum período posterior.

\subsection{Fatores que podem atrair as meninas para cursos de TI}

Para identificar fatores que podem atrair meninas para cursos de TI (FPATI), foram analisadas as respostas dadas pelas discentes à questão: "5. Na sua opinião, o que pode incentivar ou despertar o interesse das mulheres pela área de TI?" e as respostas das egressas à questão: "7. Na sua opinião, o que pode incentivar ou despertar o interesse das mulheres pela área de TI e sua perseverança em terminar um curso na área?" Também foram analisadas as respostas dadas pelas discentes à questão: "4. Por que você escolheu este curso? O que você acha que influenciou em sua decisão?". Os fatores identificados foram os seguintes:

- FPATI1: Conhecer experiências de outras mulheres da área de TI

- FPATI2: União e incentivo mútuo entre as mulheres da área

- FPATI3: Conhecer melhor os cursos da área e o mercado para egressos

- FPATI4: Mostrar que TI também é para meninas

- FPATI5: Incentivo por meninas que já são da área ou por amigos, familiares e conhecidos.

- FPATI6: Realização de projetos, palestras e cursos que divulguem e incentivem a participação feminina na área

- FPATI7: Proporcionar o contato das meninas com a área de computação (e.g. com programação) e com jogos

- FPATI8: Despertar a curiosidade pela área em meninas desde a infância

- FPATI9: Divulgar formas de superar dificuldades nesses cursos

- FPATI10: A disponibilidade de cursos da área de TI próximos ao local de residência das estudantes

\footnotetext{
${ }^{9}$ https://goo.gl/oyeegL
} 


\subsection{Fatores que motivam as meninas a concluírem cursos de TI}

Para identificar fatores que podem motivar as meninas a concluírem cursos de TI (FMCC), foram analisadas as respostas dadas pelas discentes à questão: "6. Quais os principais fatores que lhe motivam a continuar no curso? e das egressas à questão: "5. Quais os principais fatores que lhe motivavam a continuar no curso enquanto era aluna?". Os fatores identificados foram os seguintes:

- FMCC1: Gostar da área e de disciplinas como programação

- FMCC2: Servir de exemplo para outras mulheres

- FMCC3: Poder contribuir para o desenvolvimento tecnológico

- FMCC4: Apoio de familiares, colegas, professores e amigos

- FMCC5: Oportunidades no mercado de trabalho

- FMCC6: Possibilidade de poder trabalhar em diferentes áreas

- FMCC7: Realização profissional e acadêmica

- FMCC8: Já trabalha com a área de TI

- FMCC9: Busca por conhecimento

- FMCC10: Por faltar pouco tempo para se formar

- FMCC11: Vontade de sair do país

- FMCC12: Apoio da comunidade da área de TI ou de grupos para apoiar meninas

- FMCC13: Retorno financeiro da área

- FMCC14: Disciplinas ofertadas nos cursos e participação em projetos

- FMCC15: Exemplos de pessoas que tiveram sucesso na área

\subsection{Fatores que diminuem a motivação das meninas a concluírem cursos de TI}

Para identificar fatores que diminuem a motivação das meninas a concluírem cursos de TI (FDMCTI), foram analisadas as respostas dadas pelas discentes à questão: "7. Quais os principais fatores que diminuem sua motivação em continuar no curso? e das egressas à questão: "6. Quais os principais fatores que diminuíam sua motivação em continuar no curso enquanto era aluna? ". Os fatores identificados estão listados abaixo:

- FDMCTI1: Dificuldades e reprovações nas disciplinas ou pouca afinidade com algumas delas

- FDMCTI2: A quantidade de requisitos demandados para algumas oportunidades de trabalho na área ou a falta de oportunidades na área

- FDMCTI3: Dificuldade em se enturmar

- FDMCTI4: Pressão psicológica

- FDMCTI5: Discriminação, disputas entre os sexos e preconceito

- FDMCTI6: Cansaço por conta da carga horária ou necessidade de trabalhar e estudar

- FDMCTI7: Distância da família

- FDMCTI8: Falta de oportunidades de participação em atividades extracurriculares

- FDMCTI9: Problemas na organização curricular do curso

- FDMCTI10: Falta de apoio por parte dos professores ou descontentamento com professores do curso

- FDMCTI11: Falta de recursos para se manter no curso

- FDMCTI12: Pouca experiência prática durante o curso para conhecer melhor o mercado

- FDMCTI13: Pouco conhecimento prévio da área antes de entrar no curso 


\subsection{Análise Geral dos Resultados e Ameaças à Validade}

Algumas das respostas que ilustram os fatores identificados nesta pesquisa estão ilustrados a seguir com o identificador da aluna $\left(\mathrm{A}^{*}\right)$ ou egressa $\left(\mathrm{E}^{*}\right)$ :

"[...] me apaixonei pela programação e esse era o curso relacionado a isso mais próximo da minha casa" (A1).

"Mostrar que essa área não é só para homens,[...] muitos feitos nessa área foram realizados por mulheres, mas infelizmente isso ainda não está muito explícito[...]."(A3)

"[...] nos primeiros anos da escola encorajando as meninas a se interessarem pelas áreas de exatas e tecnologia no geral, assim como computadores e jogos[...]."(A42)

Observou-se que foi bastante frequente a presença de respostas que reforçam a importância do contato prévio com a área de computação e de maneira especial com programação. Percebeu-se também que alguns fatores que diminuem a motivação das meninas podem também ser compartilhados pelos meninos.

Considerando o número reduzido de respostas obtido frente ao universo de mulheres na área e também a concentração das respondentes em instituições da Paraíba, não se pode dizer que este estudo apresenta todos os possíveis fatores que atraem e afastam as meninas da área de TI e ele não tinha essa pretensão. No entanto, acredita-se que este trabalho é uma fonte importante de informações para diferentes ações. Acredita-se também que os resultados obtidos podem servir de ponto de partida para futuras pesquisas de natureza quantitativa.

\section{Conclusões e Trabalhos Futuros}

Embora vários dos fatores apontados neste estudo já sejam conhecidos e abordados em diferentes trabalhos, este trabalho conseguiu estruturar uma lista inicial considerando a opinião de meninas brasileiras da área e que já estão em cursos da área de TI ou já concluíram seus cursos. Esta lista pode proporcionar diversas pesquisas futuras para investigar o quanto cada fator de fato impacta na motivação ou desmotivação das meninas para seguirem na área ou o quanto o gênero do estudante tem influểncia na indicação de cada fator, já que muitos deles impactam meninos e meninas. Ao mesmo tempo, os resultados deste trabalho podem servir de ponto inicial para diversas reflexões para atrair novos alunos e evitar a evasão. Além disso, diversas análises podem ser feitas com base nos resultados obtidos e em novas respostas aos formulários.

\section{Referências}

Aires, J., Mattos, G., Oliveira, C., Brito, A., Aragão, A. F., Alves, S., Coelho, T. e Moreira, G. (2018). Barreiras que Impedem a Opção das Meninas pelas Ciências Exatas e Computação: Percepção de Alunas do Ensino Médio. In: Ainais do $12^{\circ}$ Women in Information Technology (WIT 2018). SBC, 2018.

Almstrum, V. L. e Last, M. (2005) What attracts women to CS?. In: Proceedings of the 10th annual SIGCSE conference on Innovation and technology in computer science education (ITiCSE '05). ACM, New York, NY, USA, 378-378.

Creswell, J. W. e Poth, C. N.(2018) Qualitative inquiry and research design: Choosing Among Five Approaches. Sage, 2018.

Dantas, V F.; Figueiredo, R. V. (2018) Chá da tarde: criando uma rede de apoio entre as discentes de cursos de Computação. In: $12^{\circ}$ Women in Information Technology (WIT 2018). SBC, 2018.

Frieze, C; Quesenberry, J. L. (2019). How computer science at CMU is attracting and retaining women. Commun. ACM 62, 2 (January 2019), 23-26. 